\title{
Ueber Cyanin-Farbstoffe.
}

\author{
II. Mitteilung. \\ Herstellung von Pinacyanol durch Trioxymethylen. \\ Von Terutaro Ogata.
}

Physik. u. Chem. Forchungsinstitut.

(Comm. by R. MAJima, M.I.A., May 12, 1927.)

Es gibt verschiedene Methoden der Pinacyanol-zubereitung in der Literatur, z.B. die Anwendung von Formaldehyd, Trihalogenmethan, Ortho-ameisensäureäthylester und atmosphärischem Kohlensäureanhydrid als Quelle des zentralen Methenylradikals des Pinacyanolmoleküls.

Als Resultat meiner Versuche, welche ich nach diesen verschiedenen Methoden ausführte, wurde erkannt, dass die höchste Ausbeute nur $37.2 \%$ beträgt, was Tabelle I zeigt.

\section{Tabelle I.}

\begin{tabular}{l|c|c}
\hline $\begin{array}{c}\text { Die Quelle von dem Zentral- } \\
\text { methenyl-radikal. }\end{array}$ & Schmp. unter Zersetz. & Die Ausbeute $(\%)$ \\
\hline (1) Formaldehyd ${ }^{1)}$ & $277^{\circ}$ & 37.2 \\
(2) Chloroform ${ }^{2}$ ) & $280^{\circ}$ & 25.0 \\
(3) Atm. $\mathrm{CO}_{2}{ }^{3)}$ & $245^{\circ}$ & 6.3 \\
(4) 0-Ameisensäurester $^{4)}$ & $289-290^{\circ}$ & 12.5 \\
\hline
\end{tabular}

In dieser Mitteilung ist als die günstigste Methode der Pinacyanolsynthese die Anwendung von Trioxymethylen anstatt Formaldehyds, Trihalogenmethans und Ortho-ameisensäuresters, beschriëben. Die Maximalausbeute des Farbstoffes beträgt dabei 75.8\% der Theorie.

Die Reaktion kann durch folgende Gleichung ausgedrückt werden:

1) D.R.P. No. 172118.

2) D.R.P. No. 200207.

3) D.R.P. No. 155541.

4) W. König. Ber. d. deut. Chem. Gesells. 55, 3293 


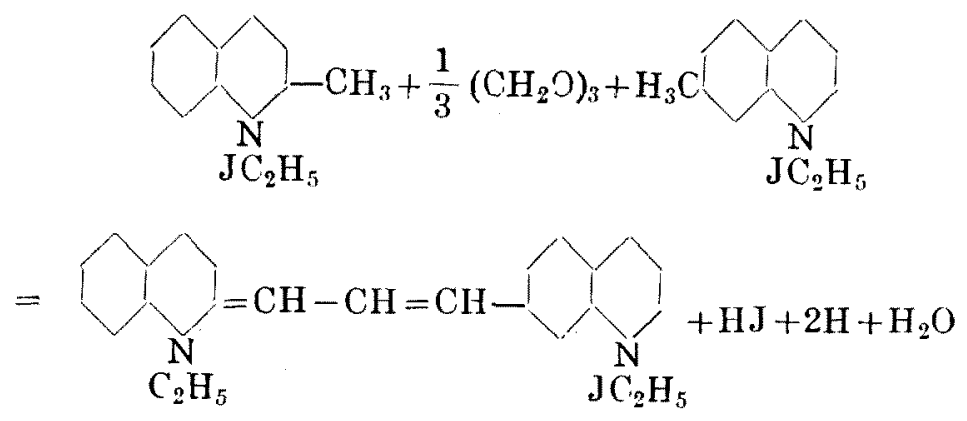

Mehrere Versuche wurden gemacht, um die günstigsten Bedingungen zu finden.

Die Resultate der Experimente bei Anwendung von Trioxymethylen sind in folgender Tabelle angegeben.

Tabelle II.

\begin{tabular}{|c|c|c|c|c|c|}
\hline $\begin{array}{l}\text { Chinaldin- } \\
\text { jodäthylat } \\
(\mathrm{g})\end{array}$ & $\begin{array}{c}\text { Chinolinjod- } \\
\text { äthylat (g) }\end{array}$ & $\begin{array}{c}\text { Trioxy- } \\
\text { methylen }(\mathrm{g})\end{array}$ & Natrium (g) & Schmp. & Ausbeute $(\%)$ \\
\hline 3 & 0 & 0.12 & 0.12 & $285-286^{\circ}$ & 40.0 \\
\hline , , & " & , & , & $287-288^{\circ}$ & 39.6 \\
\hline " & $"$ & 0.15 & ", & $282^{\circ}$ & 37.5 \\
\hline ", & ," & 0.20 & " & $285-286^{\circ}$ & 30.0 \\
\hline ", & ," & 0.30 & , & $290^{\circ}$ & 16.7 \\
\hline " & 3 & 0.10 & 0.24 & $277-278^{\circ}$ & 75.8 \\
\hline ", & , & 0.15 & ", & $283-284^{\circ}$ & 72.5 \\
\hline ", & ", & 0.20 & ", & $291-292^{\circ}$ & 65.8 \\
\hline
\end{tabular}

Dadurch ist gefunden, dass Überschuss an Trioxymethylen eine bedeutende Verminderung der Farbstoffausbeute bringt. Wahrscheinlich ist diese Erscheinung der reduzierenden Eigenschaft des Trioxymethylens zuzuschreiben. Daher bringt eine kleine Verminderung von Trioxymethylen grössere Ausbeute.

Die Wirkung zweier Moleküle von Natrium auf zwei Moleküle von Chinaldinjodäthylat und ein drittel Molekül von Trioxymethylen im Beisein von zwei Molekülen Chinolinjodäthylat ergibt maximale Ausbeute.

Alle diese Farbstoffe (ausgenommen 3 in Tabelle I) sind analytisch rein und die Absorption und Sensibilisierungsgrenzen sind praktisch dieselben. 
Der Farbstoff (4) in Tabelle I ist ein besserer Sensibilisator als die andern. Er enthält keine die Sensibilisierungswirkung hindernde Verunreinigung.

Aber ich bemerkte, dass der Farbstoff von höchster Reinheit durch Behandlung mit geeigneten Lösungsmitteln, z.B. Essigsäureanhydrid aus jedem Rohfarbstoffe gewonnen werden kann.

Diese Farbstoffe, entweder einzeln oder gemischt, schmelzen bei $296^{\circ}$ unter Zersetzung.

Ferner bemerkte ich, dass Trioxymethylen-pinacyanol ebenso wie Formaldehyd-pinacyanol ${ }^{13}$ durch konz. Salpetersäure $54.5 \%$ Chinolinsäureäthylnitrat und $83.2 \% \mathrm{~N}$-äthyl- $\alpha$-Chinolon liefert.

6, 6'-Diäthoxy-pinacyanol bildete sich auf ganz ähnliche Weise. Der Zusatz von Chinolinjodäthylat vergrössert die Ausbeute des Farbstoffs.

Zuletzt wurde gefunden, dass Pikolinalkyljodid und eine grosse Menge von Trioxymethylen einen schönen blauviolletten Farbstoff ergibt, welcher sich mit Säuren verbindet, z.B. Kohlensäure, Essigsäure, Salzsäure, Schwefelsäure und Salpetersäure. Die Alkohollösung dieser Salze ist schwach grün bei gewöhnlicher Temperatur und blauviollet bei wärmerer, wird aber schwach grün, sobald die Temperatur sinkt.

1) W. H. Mills and F. M. Hamer. Chem. Soc. $117,1550$. 